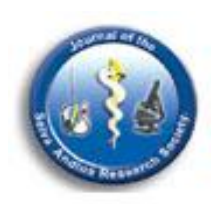

\title{
Creación de Journal of the Selva Andina Biosphere
}

\section{J Selva Andina Biosph. 2014; 2(1):1.}

La problemática ambiental, asociada a la seguridad alimentaria, conservación del medio ambiente, la biodiversidad, el rescate del conocimiento ancestral y los enfoques de desarrollo acordes al mundo actual, han sido motivo para que la Sociedad Selva Andina Research Society, y el Departamento de Enseñanza e Investigación en Bioquímica \& Microbiología de lugar al nacimiento de la revista científica Journal of the Selva Andina Biosphere, que surge como alterativa para que los investigadores, profesionales independientes, docentes universitarios, estudiantes de postgrado y pregrado en las áreas de Agronomía, Medio Ambiente, y ramas afines a la gestión y protección del medio ambiente, puedan hacer visibles sus publicaciones por este medio.

$\mathrm{Si}$, sumamos la generación de información científica que produce las universidades e institutos de investigación en ésta área del conocimiento, veríamos la amplia gama de temáticas que se aborda día a día, y su impacto en la sociedad es casi desapercibida, debido a que dicha información se la mantiene en documentos en las bibliotecas o medios magnéticos que no son de aplicación y menos de benéfico para aquellas instancias que están en busca de información local, que les brindaría un apoyo en la elaboración de programas, proyectos, o quizá permitan hacer algunas mejoras en el área de la agricultura, medio ambiente y sus ramas conexas. No obstante creemos que a partir de lo que se publique en Journal of the Selva Andina Biosphere, seamos el articulador de estos procesos que a la larga contribuyan a la sociedad en su conjunto.

Por lo anterior, seguimos trabajando para hacer que la revista siga profundizando estas temáticas que son de suma importancia en el desarrollo de la ciencia y tecnología, que garanticen la seguridad alimentaria en un marco del respeto de la naturaleza a la que nos debemos, dado que la agricultura ha sido, es y será el pilar fundamental de la existencia de la humanidad, en sus diferentes niveles sociales, culturales y económicos.

Journal of the Selva Andina Biosphere, está en ese proceso, actualmente estamos indexados en Dialnet, y seguimos en proceso de evaluación de otros portales de prestigio internacional que nos permitirán ampliar la visibilidad de la revista, de ahí que invitamos cordialmente a los investigadores, profesionales independientes, estudiantes de pregrado y posgrado, locales, nacionales y de todo el mundo, contamos con profesionales de reconocido prestigio internacional, en el comité editorial, que dan la calidad y garantía en sus evaluaciones antes de ser editada la revista.



